the final choice of treatment. In a recent survey on the management of laryngeal cancer in the United Kingdom and Ontario, Canada, Gaze et al found that $84 \%$ of otolaryngologists and $96 \%$ of clinical oncologists would recommend primary radiotherapy for $\mathrm{T}_{3}, \mathrm{~N}_{0}, \mathrm{M}_{0}$ laryngeal cancer

The recent advances in stomal valves and speech buttons are excellent news for patients in whom laryngectomy is inevitable, but we should still strive to allow as many patients as possible to retain their larynges with good speech function.

MARGARET DALY PERRIC CRELLIN MARK GAZE

Department of Clinical Oncology, HUGH MACDOUGALL Western General Hospital, Edinburgh EH4 2XU

1 Gleeson M. Voice after laryngectomy. BMf 1992;304:2-3. (4 January.)

2 Kaplan MJ, John ME, Clark DA, Cantrell RW. The roles of surgery and irradiation. Cancer 1984;53:2641-8.

3 Harwood AR, Bryce DP, Rider WD. Management of T3 glottic cancer. Arch Otolaryngol 1980;106:697-9.

4 McNeil BJ, Weichselbaum R, Pauker SG. Speech and survival. Tradeoffs between quality of life in laryngeal cancer. $N E$ Englf Tradeoffs between quati $1981 ; 305: 982-7$.

5 Gaze MN. Mackillop WJ, O'Sullivan B, Gilbert R, Maki E, Lundgren $\mathrm{J}$. The management of laryngeal cancer. A comparison of practice in the United Kingdom and Canada. Clin Oncol 1991;3:296.

SIR, - As a speech and language therapist working primarily with patients with head and neck cancer, and particularly patients who have had a laryngectomy, I wish to respond to Michael Gleeson's editorial on voice after laryngectomy.' I work in one of the British centres for surgical voice restoration (the technical term for voice valving). We offer this as the first option for communication after laryngectomy, except in rare cases in which the prognosis is particularly poor. It is important to note that the voice valve merely allows lung air to produce the sound for speech. As with normal speakers, this sound is modified by the oropharyngeal tract and the articulators. Voice is a small but fundamental part of speech. The editorial does not distinguish clearly between voice and speech.

Voice valves can also be offered to patients who have had a laryngectomy who have undergone more extensive resection with, for example, gastric pull up repair. Valves have been especially successful in those with jejunum grafts, where the quality of voice afforded is more acceptable than that with gastric pull up. These are patients who, as Gleeson says, would have had little chance of attaining satisfactory voice with traditional methods.

With regard to cost, maintenance may not be too expensive, but, especially in the early stages, the call on the time of medical staff and speech therapists is great.

No one can overestimate the far reaching effects that loss of voice has on lifestyle and personality. The availability of voice valves goes some way towards minimising these and providing successful rehabilitation.

Marie Curie Rehabilitation Centre,

J M DAWSON

Royal Marsden Hospital,

London SW3 6JJ

1 Gleeson M. Voice after laryngectomy. BMF 1992;304:2-3. 4 January.)

SIR, - In his editorial on the quality of speech after laryngectomy Michael Gleeson is less than fair when reviewing the evidence for the effectiveness of non-surgical treatments.

At least two substantial British prospective randomised studies of radiotherapy with or without chemotherapy have shown that many patients with advanced laryngeal cancer $\left(T_{3}, N_{0}, M_{0}\right.$ and upwards, by Gleeson's chosen classification of stage) can be cured." Not only is this clearly contrary to his statement that "Others present with advanced disease, and for these unlucky patients total laryngectomy provides the only hope of long term survival" but analysis of "salvage" surgery that is, total laryngectomy after failure of nonsurgical treatment-has confirmed that avoiding early surgery does not seem to prejudice overall survival (H R Grant et al, 5th European conference on clinical oncology, London, September 1989). This study showed conclusively that over half of the patients, particularly those with $\mathrm{T}_{3}$ rather than $\mathrm{T}_{4}$ laryngeal cancers, never required surgical treatment and were therefore cured, particularly if the tumour had not spread to lymph nodes in the neck, without laryngectomy and consequent loss of voice.

It should be emphasised again that loss of voice is a majority penalty of laryngectomy, however effective the rehabilitation, follow up, and supportive care. Every effort should be made to avoid this tragedy by offering the most powerful form of non-surgical treatment as the primary treatment. Fortunately, this message seems to have filtered through to most British specialist centres, although it is apparently not yet widespread in the United States, even though a recent American based randomised study again showed that only about one third of patients with advanced laryngeal cancer required laryngectomy for relapse after maximum non-surgical treatment.

J S TOBIAS

University College Hospital

London WC1E 6AU

Gleeson M. Voice after laryngectomy. BMf 1992;304:2-3. 4 January

2 SECOG Participants. A randomised trial of combined multi-drug chemotherapy and radiotherapy in advanced squamous cell carcinoma of the head and neck. Eur $\mathcal{f}$ Surg Oncol 1986:12:289-95.

3 Gupta NL, Pointon RCS, Wilkinson PM. Randomised clinical trial to contrast radiotherapy with radiotherapy and methotrexate given synchronously in head and neck cancer. Clin Radiol 1987;38:575-81.

4 Department of Veterans Affairs Laryngeal Cancer Study Group Induction chemotherapy plus radiation compared with surgery plus radiation in patients with advanced laryngeal cancer. NEngl F Med 1991;324:1685-90.

\section{Appropriate chemotherapy for palliating advanced cancer}

SIR, - R D Rubens and colleagues' suggestion that a consensus view on good clinical practice for the management of a particular cancer should be published ${ }^{\prime}$ is to be applauded, provided the consensus view includes the best available treatments validated by research and is not just restatement of traditional treatments, which will do little to improve the treatment of cancer.

Although the treatment of multiple myeloma remains palliative, considerable prolongation of good quality life is possible, and the Medical Research Council's fifth myeloma trial, which compared melphalan with combination chemotherapy, showed a clear survival advantage for combination chemotherapy. This large randomised trial is the first Medical Research Council myeloma trial to show a significant improvement in survival with the new regimen of adriamycin, carmustine, cyclophosphamide, and melphalan over the well established melphalan regimen. At four years 31\% of patients treated with the combination were alive as opposed to $16 \%$ in the melphalan group.

A second important advance has been the prolonged duration of the plateau phase in patients treated with interferon alfa as shown in a smaller randomised study ${ }^{3}$; this is the subject of a larger Medical Research Council study of interferon alfa$\mathrm{b}$ given during the plateau phase, which was started in April 1989.

These two well documented advances surely deserved a mention in Rubens and colleagues brief discussion of the treatment of myeloma, in preference to trials of high dose chemotherapy with bone marrow transplantation, which are at present too small or in which long term follow up is insufficient to determine outcome. Multiple myeloma is perhaps an example of a cancer for which achieving an accurate consensus view of optimal management from published reports required more detailed and wider consultation than was undertaken.

MALCOLM S HAMILTON

Torth London Blood Transfusion Centre,

London NW9 5BG

Rubens RD, Towlson KE, Ramirez AJ, Coltart S, Slevin ML Terell C, et al. Appropriate chemotherapy for palliating advanced cancer. $B M 7$ 1991;304:35-40. (4 Januiary.)

2 MacLennan ICM, Kelly K, Crockson RA, Cuzick J, Chapman C. Results of the MRC myelomatosis trials for patients entered since 1980. Hematol Oncol 1988;6:145-58.

Mandelli F, Tribalto M, Avvisati G, Cantonetti M, Petrucci MT Boccadoro M, et al. Recombinant interferon alfa- $2 \mathrm{~b}$ (Intron $\mathrm{A}$ as post induction therapy for responding multiple myeloma patients. M84 protocol. Cancer Treat Rev 1988;15/supp A):43-8.

SIR,-As a director of public health, I welcome efforts by the $B M \mathcal{F}$ to provide practical help to health authorities and general practitioners in their new purchasing role. Given the breadth of health authorities' remit, the advice given in R D Rubens and colleagues' review of appropriate chemotherapy for palliating advanced cancer is most useful.

What this and similar articles do not do is help authorities to make decisions when resources are scarce. Though Rubens and colleagues acknowledge that the costs of such services need to be weighed against potential benefits, no evidence is presented to support this aspect of decision making. As well as considering the utility of any treatment or intervention, as the authors suggest, it is important to assess its cost effectiveness. How else will public health directors and their health authorities be able to make informed choices about whether to spend money prolonging the quality of life of patients with lung cancer or to shift more resources into preventing smoking related disease? BOBBIE JACOBSON

Department of Public Health,

City and Hackney Health Authority,

London N1 5LZ

Rubens RD, Towlson KE, Ramirez AJ, Coltart S, Slevin ML, Terrell C. Appropriate chemotherapy for palliating advanced cancer. BMI 1992;304:35-40. (4 January.)

\section{Overheads for clinical research}

SIR, - University departments are encouraged by the Committee of Vice Chancellors and Principals to charge realistic overheads when engaging in contract research with the pharmaceutical industry. Practices still vary widely, but nonitemised proposals for overheads of as much as $100 \%$ on research contracts are now being made in Britain.

The practice in continental Europe, according to a survey performed by the Association of the British Pharmaceutical Industry, is different. In Belgium, Switzerland, Finland, and Sweden overhead charges have never been incurred. In Norway, Germany, Ireland, the Netherlands, and Spain less than a quarter of institutions request such overheads, and invariably at a rate of less than $25 \%$. In the United States overhead charges are not always added to research grants, but the practice is more variable than in Europe. The highest rate encountered in the survey was $70 \%$, and in most cases the rate was less than $25 \%$.

There can be no objection to itemised expenses, which can be debated directly by the institution and the company concerned. High demands that 
are not itemised and not for debate may drive industrial support elsewhere in Europe and to other countries.

Association of the British Pharmaceutical Industry London SW1A 2DY

J D SWALES K B SAUNDERS

Association of Clinical Professors of Medicine.

Department of Medicine,

St George's Hospital,

London SW $170 \mathrm{RE}$

\section{Deciding whether to be a doctor}

SIR, - I agree with M J Kelly's views that sixth form students need expert help in deciding whether to embark on a career in medicine. ' For the past two years I have run a course at a large tertiary college with the specific aim of educating would be medical students about the life doctors lead so that they can make an informed choice about their future career.

The course runs for two hours a week over 10 weeks and includes information about courses, postgraduate specialist training, the nitty gritty of doctors' daily work, and interview technique with plenty of time for discussion. I include half hour individual sessions for students, aimed particularly at helping them to evaluate whether they really do want to be a doctor. The students greatly appreciate the frank discussion and game techniques that I use to get the point across.

Of 28 students whom I have seen, five subsequently decided to pursue another degree course. They are all bright, most expecting to get AAA or $\mathrm{ABB}$ grades at A level, but most have little idea of what doctors do apart from what they have seen on television programmes. They usually want to be surgeons, none wanting to be general practitioners, and they have no idea of the huge range of careers within medicine. I encourage them to get work experience-for example, in a hospital or old people's home - and to talk to their general practitioner. The college also runs a pre-health course, which includes first aid training.

I hope to engender in students the confidence and belief that they have chosen the right career for the right reasons and not because of parental and teachers' pressure, glamorous fantasies, or lack of information about alternative professions that may provide them with the same satisfaction. It is wrong that so many of our young doctors become demoralised and angry and regret their choice of career. ${ }^{2}$ It is not, however, surprising in view of the way many bright students are swept along by a tide of other people's enthusiasm and their own ignorance. Medicine is a wonderful, varied, and exciting career also full of heartache and frustration. It is our duty to educate our future colleagues and let realism prevail.

\section{Teddington}

Middlesex TW $119 \mathrm{AE}$

1 Kelly MJ. Seeing for themselves. BMf 1991;303:1598-600. (21-28 December.)

2 Parker DF. Demoralised doctors. BMF 1990;300:56-7.

SIR, $-M$ J Kelly has taken an imaginative approach in helping potential medical students to acquire insight into medical school and medical practice. ' His comment on the approach of teachers and careers advisers in schools is right; in my experience they have little idea of the demands of medicine. The fault, however, is not just on the side of the schools, for the medical schools are far from blameless.

Medical schools need to exert more authority in two areas: the selection process for medical students needs overhauling, and a firmer line on weeding out those who are misfits is needed. As the person responsible for the preregistration year in this medical school, I know that consultants are concerned that some graduates have difficulty in completing their year as a house officer. These doctors' undergraduate records often show the signs of impending disaster. The arguments for their continuing the course are as Kelly outlined; when they are challenged to account for their poor performance they give many reasons, but how seriously is their commitment to medicine questioned?

I have doubts about the adequacy of the current system of selection for medical school. A considerable financial investment is made to educate a doctor. Is a 10 minute interview, or none at all, an adequate means of deciding who should benefit from this investment? The procedure needs to be more rigorous and professional. Roberts and Porter called for a change in the selection process. ${ }^{2}$ Potential recruits to the armed services and civil service and potential national airline pilots undergo a comprehensive selection process.

Students who find their motivation to pursue a medical career wanting may find it difficult to express their fears. This may be reflected in poor reports. Students must be encouraged to seek advice; a genuine doubt about a future in medicine needs to be handled with understanding. Student counsellors, and interested members of staff, have much to offer. Students should know that such advice is available and easily accessible.

Let us ensure that those we select are of the required standard, intellectually and emotionally.

\section{St George's Hospital \\ London SW 170 OQT} 1 Kelly MJ. Seeing for themselves. BMF 1991;303:1598-600.
(21-28 December.)

2 Roberts GD, Porter AMW. Medical student selection --time for change: discussion paper. $\mathcal{F} R$ Soc Med 1989;82:289-91.

\section{High potency factor VIII concentrates}

SIR, - I am responding on behalf of the United Kingdom Haemophilia Centre Directors' Organisation to John D Cash's article on high potency factor VIII concentrates.' The article has been quoted by several purchasing authorities as evidence for lack of benefit from high purity factor VIII. Such a view is an oversimplification. Presently, most factor VIII used in the United Kingdom is of intermediate purity and is prepared, mainly by NHS fractionation laboratories, from voluntary donors. It has been in use since 1985 and found to be efficacious and safe from viral infection. Thus, continuing its use while newer products are being introduced and evaluated seems reasonable.

High purity factor VIII, free from extraneous protein, is both appropriate and desirable. Nevertheless, it should be introduced gradually and, as with any new therapeutic substance, monitored for safety and efficacy.

In 1990 the United Kingdom Haemophilia Centre Directors' Organisation issued recommendations for the treatment of haemophilia and identified certain groups that might benefit from high purity factor VIII. Firstly, patients receiving intermediate purity products who develop an allergic reaction should be changed to a high purity product; this is consistent with Cash's view.' Others include patients undergoing major surgery or receiving treatment for the first time. A high purity product provides the haemostatic dose in a smaller volume and is of particular benefit to patients with poor venous access and children. Most patients treated for the first time are children. We accept, however, that any new treatment should be of proved safety in adults before being given to children. Therefore, a paediatric haemophilia working party has been established to address this issue and to plan prospective trials. These trials will also incorporate regimens for planned prophylaxis and an appraisal of the incidence of factor VIII antibodies. Concern has been expressed that treatment with monoclonally derived high purity products is associated with an increased incidence of inhibitors. ${ }^{2-4}$

There remains the question whether high purity factor VIII prevents down regulation of the immune system. Evidence of benefit continues to accumulate, as indicated recently by de Biasi et al. ${ }^{5}$ Evans $e$ al have shown preservation of the immune system in patients treated with only one product of intermediate purity. ${ }^{6}$ If a sustained defect in the immune system is evident, however, it seems reasonable to change to treatment with a high purity product, again with careful clinical and laboratory evaluation.

At present Scotland and Northern Ireland are introducing an alternative high purity product for all patients. The product will be fractionated according to the technology of Burnouf et al. ${ }^{7}$ It will be administered within prospective clinical trials. Thus the place of high purity factor VIII is emerging and, provided it proves to be satisfactory on scientific evaluation, it will attain its rightful place in the treatment of haemophilia within a short time.

E E MAYNE

Chairman,

United Kingdom Haemophilia Centre

Directors' Organisation,

Royal Victoria Hospital,

Belfast BT12 6BA

1 Cash JD. High potency factor VIII concentrates: value not proved? BMF 1991;303:633-4. (14 September.)

Bell BA, Kurczynski EM, Bergman G. Inhibitors to monoclonal antibody purified factor VIII. Lancet 1990;336:638.

3 Kessler GM, Sachse K. Factor VIII:C inhibitor associated with monoclonal-antibody purified factor VIII concentrate. Lancet 1990;335:1403.

4 Montoro JB, Rodriguez S, Altisent C, Tusell JM. Transient factor VIII inhibitor and treatment with monoclonal-antibodyfactor VIII inhibitor and treatment with mo

5 de Biasi R, Rocino A, Miraglia E, Mastrullo L, Quirino AA. The impact of a very high purity factor VIII concentrate on the
implo impact of a very high purity factor VIII concentrate on the
immune system of human immunodeficiency virus-infected immune system of human immunodeficiency virus-infected haemophiliacs: a randomized, prospective, two-year com-
parison with an intermediate purity concentrate. Blood 1991; parison with an intermediate purity concentrate. Blood 1991;
Evans JA, Pasi JK, Williams MD, Hill FGH. Consistently Evans JA, Pasi JK, Williams MD, Hill FGH. Consistently
normal CD4+, CD8 + levels in haemophilic boys only treated with a virally safe factor VIII concentrate (BPL 8Y). Brf Haematol 1991;79:457-61.

Burnouf T, Burnouf-Radosevich M, Huart JJ, Goudemand M. A highly purified factor VIII:c concentrate prepared from cryoprecipitate by ion exchange chromatography. Vox Sang 1991; 60:8-15

\section{Impact resistance of drinking glasses}

SIR, - J P Shepherd and colleagues' letter on the impact resistance of drinking glasses has received considerable publicity in the national press. Ravenhead does not question the accuracy of the experiments, but the conclusions reached are not based on fact.

We do not agree that the drinking glasses used in attacks are usually intact, nor have we found police records to support this statement. If this is the case we find it difficult to understand how lacerations occur. We believe that glass used in "glassing" attacks, whether drinking glasses or bottles are used, is first broken to produce lethal dagger-like spikes. We agree that tempered glassware, if properly tempered, can be stronger than stress free, normal glassware, but this is only in its new, unused condition. Within hours of first being used in a busy pub the strength of tempered glassware deteriorates rapidly and it can become unstable. This is due to surface abrasion, which occurs when it comes into contact with other objects-for example, other glasses and cutlery.

We have yet to find a tempered glass that 